\title{
A CERVICAL SPINAL CORD INJURY FOLLOWING CHIROPRACTIC MANIPULATION
}

\author{
By Lawrence A. Rinsky, M.D., Glenn G. Reynolds, M.D., Robert M. Jameson, M.D. \\ and RichaRd D. HAMilton, M.D. \\ Departments of Orthopaedic Surgery, Physical Medicine and Rehabilitations, Clinical \\ Surgery and Neurosurgery, Stanford University School of Medicine, Stanford, California
}

NumEROUS neurological complications following chiropractic manipulations of the spine have been recorded. These reports have dealt with injury involving either the brainstem (Pratt-Thomas et al., 1947; Kunkle et al., 1952; Schwartz et al., 1956; Smith et al., 1962; Lorenz et al., 1972), spinal cord (Blaine, I925; Lievre, 1953; Lievre, I953; L'Ecuyer, I959; Livingstone, I97I), cauda equina (Richard, 1967), or the brachial plexus (Deshayes, 1962). Although some of the cases involved apparently normal patients, several have dealt with patients with pre-existing disease of the spine or spinal cord (L'Ecuyer, I950; Lievre, 1953; Livingston, 1971). The following is a case report of a patient with ankylosing spondylitis who developed a complete $\mathrm{C}_{4}$ tetraplegia (quadriplegia) after a manipulation of the neck.

\section{Case Report}

A 44-year-old right-handed white male was transferred to our spinal injury unit on 28 February 1973 because of tetraplegia. He had been in his usual state of health until I3 January 1973 when he slipped and fell at home in his kitchen. Upon arising, he noted pain in the back of his neck and tingling in the left arm. However, he was able to walk to bed. The following day he visited his local chiropractor who manipulated his cervical spine. The patient had had severe ankylosing spondylitis since the age of 18 . This had been quiescent for some years, but had left him with a completely ankylosed spine inflexion, and a fused left hip.

Immediately following the manipulation the patient developed profound left-sided weakness and was unable to walk unaided. He was seen at a hospital near his home and after some delay was admitted to that hospital on 15 January 1973. By that time he had progressive right-sided weakness and was unable to void. Cervical spine X-rays were difficult to interpret because of advanced spondylitis, but suggested a fracture of $\mathrm{C}_{3}-\mathrm{C}_{4}$. By I6 January 1973, the patient was almost totally tetraplegic except for weak movements of the toes in the right foot (fig. I). He was transferred to a second hospital for reduction of the fracture and immobilisation by cervical traction. An emergency cisternal myelogram demonstrated a complete block at $\mathrm{C}_{4}$.

A decompressive laminectomy was then performed which revealed a fracture through the spondylytic fusion of the $\mathrm{C}_{3}-\mathrm{C}_{4}$ interspace. $\mathrm{C}_{3}$ was displaced posteriorly to $\mathrm{C}_{4}$, causing an indentation in the dura by the superior lamina of $\mathrm{C}_{4}$. Following complete decompression of $\mathrm{C}_{3}-\mathrm{C}_{5}$ and reduction of the fracture by increasing the cervical flexion, the cord was seen to pulsate only down to $\mathrm{C}_{4}$ level. The dura was left open for further decompression (fig. 2).

His postoperative course was stormy and marked by respiratory insufficiency (necessitating tracheostomy and a respirator), pneumonia, and a sacral pressure sore because of difficulty turning him.

Reprint Requests: California Model Regional Spinal Injury Care System, Santa Clara Valley Medical Center, 75I South Bascom Avenue, San Jose, California 95128.

I3/4-A 

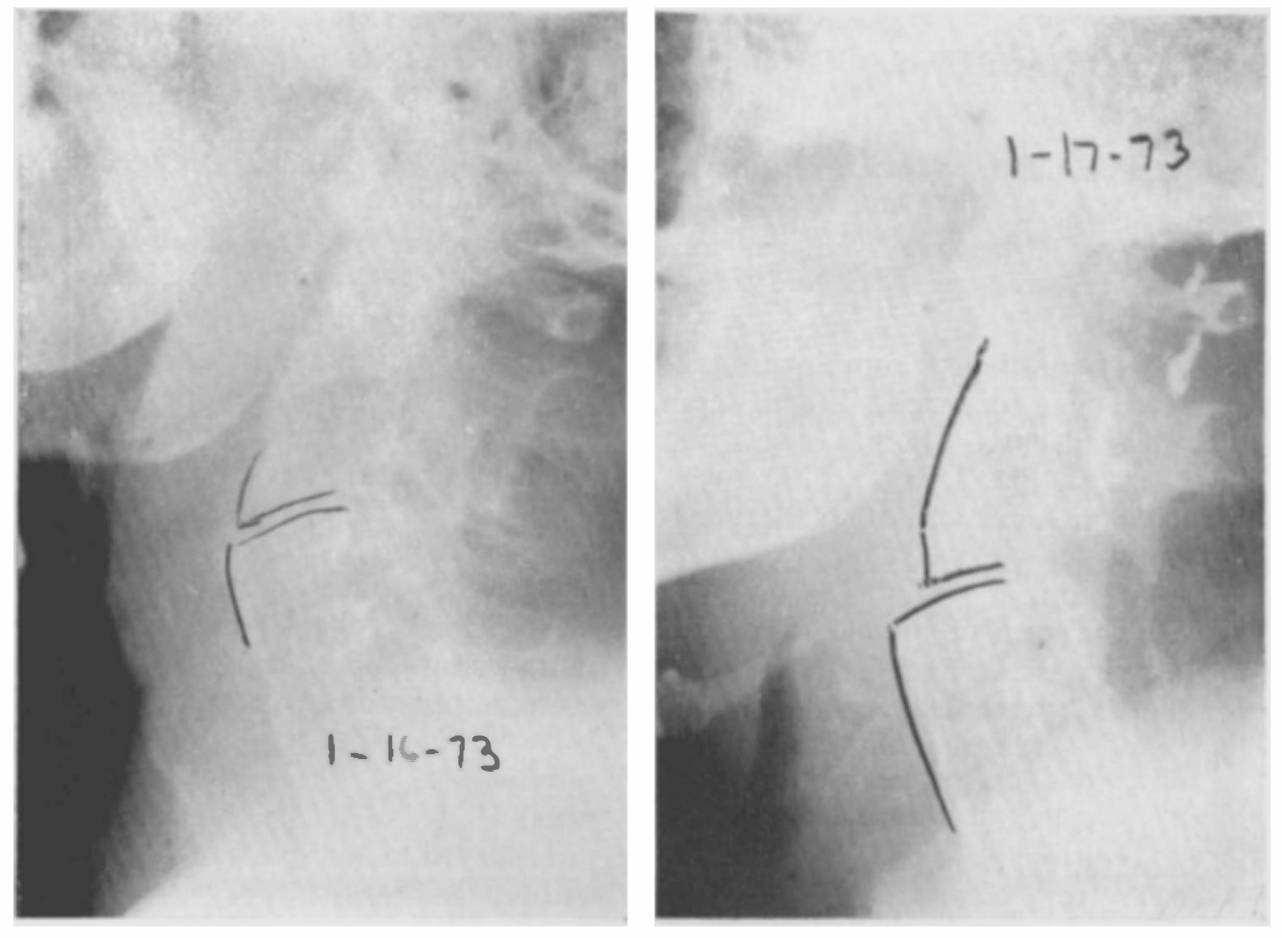

FIG. I

Preoperative films showing moderate displacement.

FIG. 2

Films taken postoperatively showing further displacement of $\mathrm{C}_{3}$ on $\mathrm{C}_{4}$.

On 8 February 1973 the patient was transferred to our spinal injury centre presenting with essentially a complete motor and sensory $\mathrm{C}_{4}$ tetraplegia. His only voluntary control of the limbs was elevation of the scapulae. All sensation ended about mid-deltoid level. The patient was able to ventilate spontaneously for periods of up to 15 minutes before fatiguing his diaphragm, but basically was respirator dependent.

Management of the patient consisted of skull traction directed essentially perpendicular to the plane of the mattress. Initial X-rays revealed a $5 \mathrm{~mm}$ posterior subluxation of $\mathrm{C}_{3}$ and $\mathrm{C}_{4}$. Subsequent X-rays revealed a satisfactory reduction with traction (fig.3). The fracture remained reduced throughout the remainder of his hospitalisation. Ventilation was accomplished using a volume respirator (Bennett, MA-3). Because of pneumonia and a fixed chest cage, compliance was greatly decreased necessitating increased respirator driving pressures.

On a programme of vigorous pulmonary toilet the patient's respiratory status gradually improved. His sacral pressure sore continued to grow in size because of the impossibility of turning him with traction maintained. Therefore, on 27 February 1973, the patient was placed in a modified halo-pelvic frame using a Roger-Anderson apparatus. This stabilised his spine so that he could be moved and given appropriate skin care (fig. 4). Six weeks post trauma he was placed in a hard collar and follow-up flexion and extension X-rays revealed cervical spine stability. His course was marked by healing of 

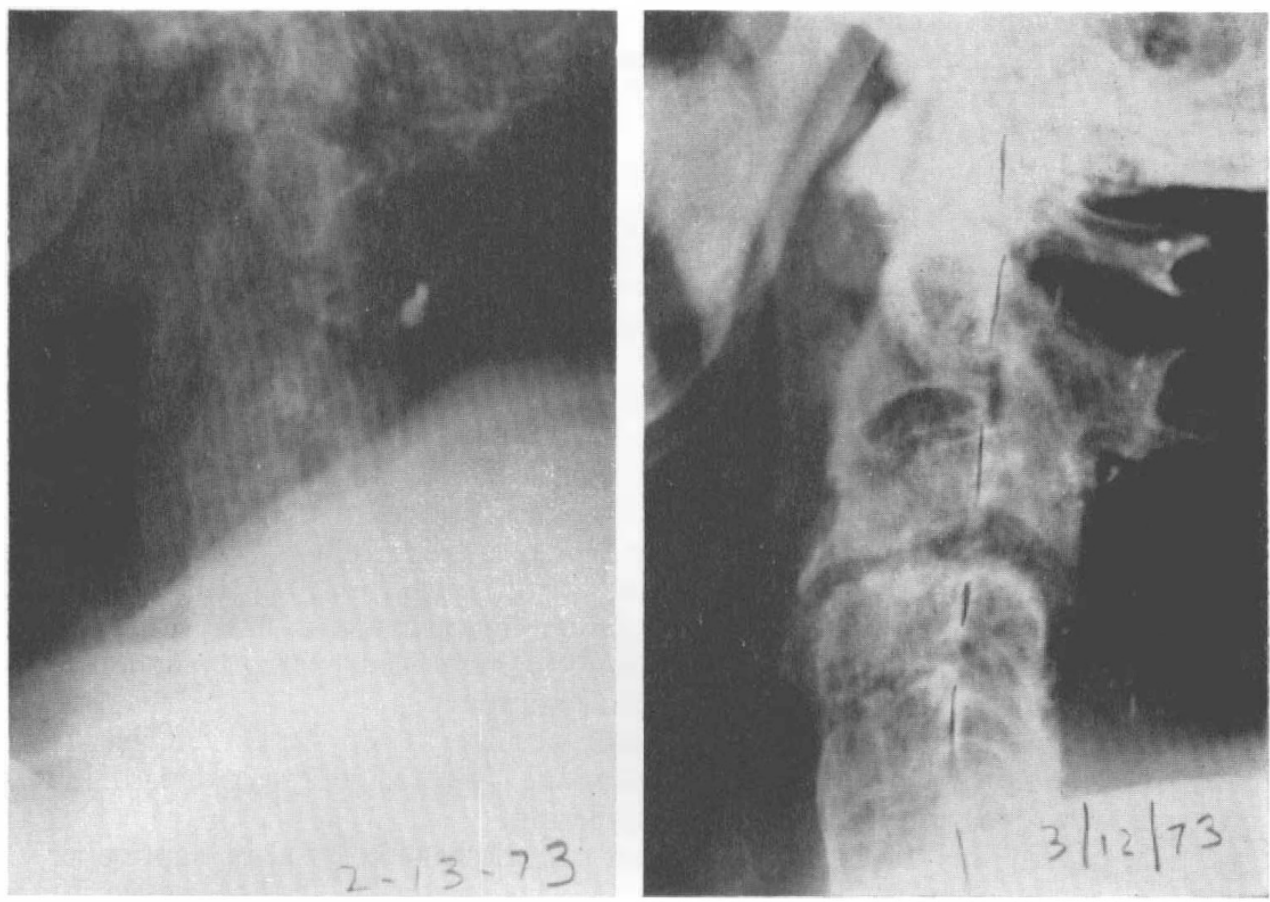

FIG. 3

Reduction of fracture by increasing flexion in traction.

Fig. 4

Two months postoperative state, relatively normal alignment.

the pressure sore and gradual improvement in ventilatory capacity so that he became respirator independent with a vital capacity of near $1000 \mathrm{cc}$. Unfortunately, the underlying $\mathrm{C}_{4}$ tetraplegia remained constant. Further care included transurethral resection of the prostate and a resection arthroplasty of the fused left hip to better facilitate nursing care and wheelchair sitting. He was discharged to a convalescent hospital on I3 October, I973.

\section{Discussion}

In our review of the literature this is the first example we have found of permanent spinal cord injury with total paralysis occurring after a chiropractic manipulation associated with a cervical fracture. Pratt-Thomas (1947) reported a patient who developed a TI paraplegia following spinal manipulation. The patient subsequently died of lung abscess. Autopsy revealed softening and necrosis of the cord below TI. No fracture or dislocation was found. A temporary luxation of the vertebral column and subsequent vascular injury was hypothesised. A similar case resulted in death from acute epidural and subarachnoid haemorrhage at $\mathrm{CI}_{1}-\mathrm{C}_{3}$ level. Again, no bony injury was found (York, I953). 
Benassy et al (1957) reported on a patient with metastatic carcinoma of the lung who became tetraplegic following chiropractic manipulation. The patient improved neurologically after immobilisation of the neck, but then died suddenly. At autopsy, no metastases or fracture of the cervical spine was found that would explain the tetraplegia.

Other patients with pre-existing spinal disease have had severe complications following spinal manipulation. Two patients with probable lumbar disc disease developed cauda equina syndromes (Fisher, I943; Richard, 1967). One patient with undiagnosed Paget's disease of the dorsal spine (Lievre, I953) developed paraplegia. Another patient with undiagnosed multiple myeloma (Livingstone, I97I) of the dorsal spine developed a T8 paraplegia. Finally, a 9-year-old girl (L'Ecuyer, 1959), with a congenital occipitalised atlas, developed reversible longtract signs following chiropractic manipulation.

Perhaps the most common neurological complication of head and neck manipulation is basilar artery thrombosis or insufficiency resulting in brain stem infarction. At least ten such cases have now been reported, of which six ended fatally (Kunkle et al., I952; Schwartz et al., 1956; Smith et al., I962; Lorenz et al., I972). Finally, Blaine (I925) reported on three forward atlanto-axial subluxations that apparently followed chiropractic manipulations. Surprisingly, none of his patients had immediate or early neurologic symptoms.

In our case we theorise that the fracture occurred when the patient fell rather than at the time of chiropractic manipulation. We feel the spinal cord injury occurred as a result of chiropractic manipulation.

The patient was discharged to a local convalescent hospital in September of 1973, and remained in the facility until I9 February 1974. He then moved into a home near his parents, with a full-time attendant. This residence is in a rural California setting, 250 miles from the spinal cord injury centre. He has not returned to the centre for follow-up since discharge, due to very difficult transportation problems.

Telephone communication with the family has revealed that he has sustained numerous episodes of pneumonia. In the spring of 1975 he was taken to a small community hospital near his home where a colostomy was performed, presumably to facilitate his bowel management.

\section{SUMMARY}

A case is presented of a permanent $\mathrm{C}_{4}$ tetraplegia following chiropractic manipulation of a patient with ankylosing spondylitis. The pertinent literature is reviewed.

\section{RÉSUMÉ}

Un cas est presenté d'un $\mathrm{C}_{4}$ tetraplégie après manouvre de chiropraxie d'un patient avec ankylosing spondylitis. Les articles importants sont presente.

\section{ZUSAMMERFASSUNG}

Ein Fall von $\mathrm{C}_{4}$ Tetraplegie nach chiropraktischer Manipulation an einem Patienten wird beschrieben, der an ankylosing spondylitis leidet. Die Literature über den Fall ist zitiert. 


\section{REFERENCES}

Benassy, J., Wolinetz, E. (1957). Quadriplegie apres manoeuvre de chiropraxie. Rev. $d u$ Rhu. et des Mal. Osteo. xxiv, 555.

Blaine, E. S. (1925). Manipulative (chiropractic dislocations of the atlas. F.A.M.A. 85, I356-1359.

Deshayes, P \& Gefreroy, Y. (1962). Un cas de paralysie plexique superierue accident d'une manipulation vertebral. Rev. du Rheu, 29, I37-139.

FisheR, E. D. (I943). Report of a case of ruptured intervertebral disc following chiropractic manipulation. Kent. M.F. 4I, I4.

Kunkle, E. C., Mueller, J. C. \& ODOM, E. L. (1952). Traumatic brain stem thrombosis: report of a case and analysis of mechanism of injury. Ann. Intern. Med. 36, I329-1 335

L'ECUYER, J. (I959). Congenital occipitalization of the atlas with chiropractic manipulations. Neb. S.M.F. 44, 546-549.

Lievre, J. A. (1953). Paraplegie due aux manoeuvres d'un chiropractor. Rev. du Rhu. et Mal. Osteo. xx, 708-709.

LivingStone, M. C. (I97I). Spinal manipulation causing injury. Clin. Orth. and Related Research, 81, 82-86.

Lorenz, R. \& Vogelsang, H. G. (1972). Thrombose der Arteria Basilaris Nach Chiropraktischen Manipulation an der Halswerbelsaule,Deutsche. Med. Woch. 97, 36-43.

Pratt-Thomas, H. R. \& Berger, K. E. (I947). Cerebellar and spinal injuries after chiropractic manipulation. F.A.M.A. 133, 600-603.

RICHARD, J. (1967). Disk rupture with cauda equina syndrome after chiropractic adjustment. N.Y.S.F. of Med. 67, 2496-2498.

SchwartZ, G. A., Geiger, J. D. \& Spano, A. Z. (I956). Postero-inferior cerebellar artery syndrome of Wallenberg after chiropractic manipulation. Arch. Intern. Med. 97, 352354.

Smith, R. A. \& Estridge, M. N. (I962). Neurologic complications of head and neck manipulations. F.A.M.A. 182, 528-531.

YoRk, V. DANIELS, 259 S.W. (2d) IO9 (Mo., I953). 